\title{
Self-Efficacy, Emotional Intelligence, Achievement Motivation and Work- Value Orientation as Predictors of Career Commitment of Bank Workers in Imo State
}

\author{
${ }^{1}$ Ohizu, Edwin Chika Phd, ${ }^{2}$ Okoiye Ojaga Emmanuel Phd \\ ${ }^{I}$ Department of Social Studies Alvan Ikoku Federal College of Education Owerri Imo State, Nigeria \\ ${ }^{2}$ Department of Educational Psychology/ G\&C Alvan Ikoku Federal College of Education Owerri Imo State, \\ Nigeria
}

\begin{abstract}
This study investigated self-efficacy, emotional intelligence, achievement motivation and work-value orientation as predictors of career commitment of bank workers in Imo State Nigeria. Using a descriptive survey research design, two hundred bankers were randomly selected from ten banks in Owerri, Okigwe and Orlu Senatorial districts of Imo State Nigeria. The instruments used were: Career Commitment Scale (CCS) 0.87, Achievement Motivation Scale-Revised 0.82, emotional intelligence scale 0.78, General Perceived Self Efficacy Scale (GPSS) 0.90, and Work value orientation scale 0.88. Three research hypotheses were tested and Pearson Product Moment Correlation (PPMC) was used to analyse data collected. The result of the study revealed that the independent variables significantly predicted career commitment of bankers as thus; Selfefficacy; $r(198)=.440, p<.05$.; Emotional intelligence $r(198)=.528, p<.05$. Achievement motivation, $r(198)$ $=.635, p<.05$ and work-value orientations, $r(198)=.715, p<.05$. Therefore financial institution(s) should make working in the banks more attractive and rewarding by giving bankers good remuneration, condition of service and appropriate attention to their career needs. If this is done bankers would be motivated to work and be committed to their career.
\end{abstract}

Keywords: Achievement Motivation, Career Commitment, Emotional Intelligence, Work-Value Orientation, Self-Efficacy, Bank and Imo State

\section{Introduction}

Nigeria bank industry is no doubt a major player in the socioeconomic development of the nation. Research have shown that financial institutions (banks) contributes to the nation's Gross Domestic Product (Central Bank of Nigeria - CBN, 2008), and economic growth through its role of mediating between the economic units that have surplus funds and those that require such funds to support their investment (Ebong, 2006). The sustenance of these noble roles depends on the level of commitment of its employees. Unfortunately, there has been increasing cases of poor career commitment among bank workers in Nigeria. Observably, it is a common occurrence in Nigerian banks where, many well dressed workers engage themselves in charting with their cell phones, gist on unofficial issues, while long cue of customers stand to be attended to by them. This level of personal-work role conflicts could in turn result to poor attention to official issues, inadequate response to the daily needs of their customers and general organizational inefficiency. When the personal and social demands interfere with the domain of work, the employees could experience less affective commitment to the organization (Ajiboye, 2008). Poor career commitment of bank employees, especially in developing countries like Nigeria, affects the quality of service, and consequently affects their satisfaction on the job.

One of the greatest contemporary challenge(s) facing organization(s) is engaging the services of committed staffs that will support the attainment of organizational goals (Morakinyo, 2010). According to Aborisade and Obioha, (2009) for the goals of an organization to be realized, human resources, amongst the various factors of production, must be properly utilized to enable employees to generate the needed level of job commitment for the attainment of the pre-determined objectives. In this regard, the progress and success of such organizations depends on the performance of its workers. Owing to these contentions, several researchers have highlighted the importance of workers commitment in organizations. Dixit and Bhati (2012) believe that employees who are committed to their organization will bring about sustained productivity. Salami (2008) posits that Organizations need committed workers in order to face the worldwide economic competition. Gbadamosi (2003) argued that workers commitment enhances performance which leads to organizational effectiveness. Similarly, Meyer, Allen, Gellatly, Goffin and Jackson (2000) reports that committed employees are more likely to remain with the organization and strive towards the organization's mission, goals and objectives. Employees with high organizational commitment and value self-esteem are motivated to maintain a positive self-perception, exert effort and engage in goal-directed behavior (Brockner, 1988). 
Although there is proliferation of studies on career commitment and other constructs, but there is paucity of research which examined combination of variables such as self-efficacy, emotional intelligence, achievement motivation and work-value orientation as predictors of career commitment of bank workers in Owerri Imo State Nigeria. Therefore, this study is designed to fill such research gaps in Nigeria. Against this background, this study investigated self-efficacy, emotional intelligence, achievement motivation and value orientation as predictors of career commitment of bank workers in Owerri Imo State Nigeria.

Self-efficacy is the belief people have in their ability to perform in a certain way or engage in a specific behaviour to achieve their desired goals. It is the belief that people are able to perform the actions required to manage difficult or novel tasks and to cope with the adversity associated with demanding situations (Bandura, 1997; Ivancevich, et al., 2005; Kreitner \& Kinicki, 2004). Virginie and Marc (2010) investigated the effect of national culture value and self-efficacy on organizational commitment in Haiti. The result of the study showed that self-efficacy is highly significant, and is the main predictor of organizational commitment. Perceived efficacy plays a key role in human functioning because it affects behaviour not only directly, but by its impact on other determinants such as goals and aspirations, out come expectations and perception of impediments and opportunities in the social environment (Bandura, 1995, 1997). They also influence the course of action people choose to pursue the challenges and goals they set for themselves and their commitment to them, how much effort they put forth in given endeavors, the outcomes they expect their efforts to produce and how long they persevere in the face of obstacles. Masood, Rabia and Kashif (2013) found that self-efficacy is fundamental to positive organizational results such as organizational commitment and job satisfaction. Self-efficacy influences emotional response of individuals. Jobs become more enjoyable when individuals are more competent and confident (Hartline and. Ferrell, 1996.). Moreover, self-efficacy also makes employees more confident due to its underlying basic regulatory skill to resolve conflicts that might arise with colleagues, to overcome dissatisfaction, deriving more job satisfaction (Bandura, 1977).

Also, emotional intelligence has been found to be predictive of human behavior. It is the ability to perceive and express emotion, assimilate emotion in thought, understand and reason with emotion and regulate emotion in the self and others (Mayer et al., 2000). In this regard, Cherniss (2001) reported that emotionally intelligent people display cooperation, commitment and creativity which are important for organizational effectiveness. Emotional intelligence (EI) has been linked to job performance and emotional labour (Prati, 2003; Law et al., 2004). Understanding and regulation of one's emotions as well as understanding other's emotions are factors that affect intrapersonal well-being and interpersonal relations which also affect workers. Some researchers found that emotional intelligence was positively correlated with organizational commitment of some workers (Carmeli, 2003; Nikolaou and Tsaousis, 2002; Rozell et al., 2004). Therefore, it is expected that workers having high emotional intelligence will also be highly committed to their organizations.

Thus, achievement motivation is the desire to perform in terms of a standard of excellence or to be successful in competitive situations. Persons who have high need for achievement (nAch) assume personal responsibility for the solution of tasks or problems, set moderately difficult goals, take calculated risks, and have strong desire for feedback on their performance as indexed by compensation (Lawson \& Shen, 1998). Previous researchers found significant relationship between need for achievement and organizational commitment (DoddMcCue and Wright, 1996; Mannheim et al., 1997). Most researchers agree that motivation is important in work organizations; and that individual employees attempt to satisfy many needs through their work and through their relationship with an organization $(\mathrm{Li}, 2006)$. Hence employees with high need for achievement will likely to be more committed to their organizations.

Tahir. et.al (2008) reports that significant relationship exist between motivation and employees performance. Motivation approaches definitely satisfy the needs of the employees and in return, the employee repays it through their hard work. Identifying the needs and answering it is the most basic approach of every organization to earn the commitment of the employees (Chughtai, 2008). With a well motivated workforce, an employee's performance can be manifested on the organizational effectiveness, which allows the individuals to focus on the development of their work, in terms of behaviour, skills and knowledge, ethics and effectiveness. It has been noted that motivation tends to energize the workforce which can result in their expected job performance (Byham and Moyer, 2005). Again, the motivational process increases or influence the job performance and other work outcomes of an individual that can reach to the employees' outmost performance and even their jobs satisfaction (Strain, 1995 and Chughtai, 2008).

Also, Malka and Chatman (2003) defined work value orientations as 'work-related reinforcement preferences, or tendencies to value specific types of incentives in the work environment. Thus, work value orientations are individual preferences rather than 'ought standards' that should be preferred (Dose, 1997). Intrinsic and extrinsic work value orientations probably give rise to the formulation and pursuit of intrinsic and extrinsic work goals, respectively. Work goals are more specific than work value orientations because they refer to a particular object or end state that is pursued (Oishi, Schimmack Diener, \& Suh, 1998; Schwartz, 1994), whereas work value orientations are more general and abstract, because they reflect employees' general 
preferences towards their jobs. In tandem with many other value researchers (De Witte, 2004; Grouzet et al., 2005; Rohan, 2000; Schwartz, 1994), work goals are considered to be expressions or manifestations of higherorder work values.

Sock and Mui (2012) investigated the preferred work values and career commitment of Generation Y teachers in Malaysia, as well as the moderating effect of cultural orientation on the work values-career commitment relationship of Generation Y teachers. The finding indicates that work values explain $17 \%$ of the variance of career commitment. In addition, intrinsic work values are correlated to career commitment at $r=.36$. Cultural orientation is also found to have significant impact on the work values-career commitment relationship of Generation Y teachers. Thus, Shahid, Asif, Mohammad, Muhammad and Ansir (2012) reports that the prominent player in determining the career salience was culture. Culture was a combination of values, beliefs and norms and it is shared among the individuals. Value orientation in any organization mostly focused on internal system of organization and looking for competitive advantage, it encouraged openness to new thoughts and prepared internal capabilities to adopt new ideas, process, or product successfully. Therefore, it is the motivation of this study to investigate the predictive effect of self-efficacy, emotional intelligence, achievement motivation and work-value orientation on career commitment of bank workers in Imo State.

\section{Theoretical Framework}

This study is anchored on Meyer and Allen (1997) three-components model (TCM) of organizational commitment. The model argues that organizational commitment has three distinctive components: The affective, continuance and normative commitments. The affective commitment is the individuals' emotional attachment to an organization. If employees have a high level of affective commitment, the employees will enjoy their relationship with the organization and are likely to stay. Similarly, the continuance commitment is the degree with which the employees believe that leaving the organization would be costly (Meyer \& Herscovitch, 2001). Thus, employees with high level of continuance commitment will stay with an organization because they feel that they must stay. For example, they may feel quitting the job may lead to an unacceptable length of unemployment. On the other hand, they may feel that they will lose a certain degree of status if they leave a well-respected organization such as a top law firm, a well known bank or research company. Furthermore, normative commitment is degree the employees feel obligated to the organization or believe that staying is the right thing to do (Meyer and Allen, 1997). Thus, the application of this model to the present study is crucial as it will offer the opportunity for understanding the functional components that could determine an individual's commitment in any work environment. The bank, therefore, is a very important sector of the economy involved in various developmental functions. As such, the progress and success of the bank industry in delivering these noble functions, practically depends on their employees level of commitment to work. In this regard, the three component model (TCM) provides the bases for understanding workers commitment in organizations.

\section{Purpose of study}

The purpose of this study is to investigate the predictive effect of self-efficacy, emotional intelligence, achievement motivation and work-value orientation on career commitment of bank workers in Imo State. A combination of these variables has not been used to investigate the career commitment of bank workers. Therefore, this study is crucial because it will provide an insight on the relevance of these variables to career commitment of workers.

\section{Hypotheses}

There is no significant relationship between self-efficacy and career commitment of bank workers. There is no significant relationship between emotional intlligence and career commitment of bank workers. There is no significant relationship between achievement motivation and career commitment of bank workers. There is no significant relationship between work-value orientations and career commitment of bank workers.

\section{Research Design}

\section{Methodology}

This study adopted a descriptive survey research design in which the researcher cannot manipulate the variable of interest. Questionnaire was the instrument used to collect data from the respondents on the studied variables. The population for the study consists of all bank staff in Imo State Nigeria. A total of 200 participants were used for the study. The number comprises of twenty (20) staff male and female randomly selected from ten (10) banks in owerri, okigwe, and orlu senatorial districts of Imo State. This number amount to two hundred (200) staff used for the study. 
Self-Efficacy, Emotional Intelligence, Achievement Motivation and Work- Value Orientation ....

\section{Instruments}

Career commitment was measured using a Career Commitment Scale (CCS) developed and validated by Carson and Bedeian (1994), based on the conceptualization and definition of career commitment as ones motivation to work in a chosen vocation. The scale consists of twelve (12) items designed on a 5-point likert format ranging from strongly disagree to strongly agree. Increasing scores imply higher career commitment while decreasing scores imply the converse. The scale has reported an internal consistency of 0.76 and a reliability of 0.87 using a two week test re test procedure. Some of the items on the scale are (1) My Line of work/career field is an important part of who I am (2) I do not feel emotionally attached to this line of work/career field. (3) I strongly identify with my chosen line of work/career field.

Achievement Motivation was measured using the Achievement Motivation Scale-Revised (Lang \& Fries, 2006). The AMS-R consist of 15 items with a 5-point rating scale and internal consistencies of .69 and .82, respectively. The AMS-R is based on ideas by McClelland. This scale assumes that achievement motivation can be viewed as a trait.

Emotional intelligence was assessed with emotional intelligence scale developed by Shutte, Malouff, Hall, Haggerty, Cooper, Golden and Dornheim (1998): It is a thirty-three (33) item scale structured on a 5 point likert format ranging from Strongly disagree (1) to Strongly agree (5). High score indicated increased level of emotional intelligence, while low scores indicated decreased level of emotional intelligence. The scale reported reliability co-efficient Cronbach alpha of 0.78 using a two week test re-test reliability technique (Shutte et al, 1998). Examples of items on the questionnaire are: 1) I am aware of my emotions as I experience them; 2) When I am in a positive mood, solving problems is easy for me; 3) I like to share my emotions with others; 4) I have control over my emotions etc.

General Perceived Self Efficacy Scale (GPSS) developed by Schwarzer and Jerusalem (1995) was used to assess the self efficacy of the participants. It is a 10 item statement using a four point scale ranging from (1) Not at all true to (4) Exactly true. The scale reported high internal consistency with a cronbach ranging from .75 and .90 (Schwarzer \& Jerusalem, 1995). Examples of items on the questionnaire are: 1. I can solve most problems if I invest the necessary effort as a banker 2 . I can handle whatever comes my way as a banker, etc

Work value orientation of participants was measured using intrinsic and extrinsic work value scale by Knoop (1994). The scale contains eight items that represented intrinsic and extrinsic work values. Most of the four intrinsic work value items (i.e. 'an opportunity to use initiative', 'a job that is interesting', 'a job that meets one's abilities', 'a responsible job') and most of the four extrinsic work value items (i.e. 'good pay', 'good job security', 'not too much pressure' and 'generous holidays') are identical to items used in previous research (Ros et al., 1999). Participants reported the extent to which they valued each of them $\left(\begin{array}{llll}1 & 1 / 4 \\ \mathrm{important} & 0 & 1 / 4 & \text { not }\end{array}\right.$ important). The scale reported reliability co-efficient Cronbach alpha of 0.88 .

\section{Procedure}

The researchers seek the permission of the management and staffs of the banks used for the study. The purpose of the study was equally explained to them after which the instruments were administered on them and collected back.

Method of Data Analysis

The data collected were analysis using Pearson Product Moment Correlation.

\section{Hypothesis One}

\section{Results}

There is no significant relationship between self-efficacy and career commitment of bank workers.

Table 1. PPMC summary showing significant relationship between self-efficacy and career commitment of bank workers.

\begin{tabular}{|lllllll|}
\hline Variables & N & Mean & SD & R & Df & P \\
career commitment of bank workers & 200 & 41.23 & 10.23 & .440 & 198 & Sig \\
self-efficacy & 200 & 24.34 & 4.92 & & &
\end{tabular}

Table 1 shows that self-efficacy significantly correlates with career commitment of bank workers $\mathrm{r}(198)=.440$, $\mathrm{p}<.05$. The mean and standard deviation for self-efficacy is 24.34 and 4.92 respectively. With this result the Ho: is thus rejected.

\section{Hypothesis Two}

There is no significant relationship between emotional intelligence and career commitment of bank workers. 
Self-Efficacy, Emotional Intelligence, Achievement Motivation and Work-Value Orientation ....

Table 2 PPMC summary showing significant relationship between emotional intelligence and career commitment of bank workers

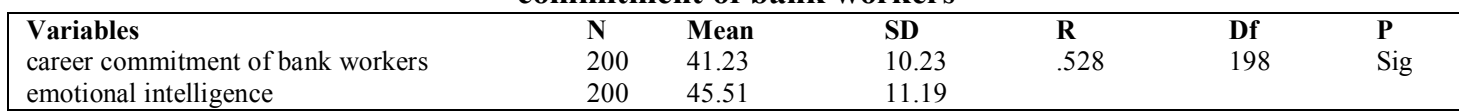

Table 2 shows that emotional intelligence correlates with career commitment of bank workers $\mathrm{r}(198)=.528, \mathrm{p}<$ .05 . The mean and standard deviation for emotional intelligence is 45.51 and 11.19 respectively. With this result the Ho: is thus rejected.

Hypothesis Three

There is no significant relationship between achievement motivation and career commitment of bank workers.

Table 3. PPMC summary showing significant relationship between achievement motivation and career commitment of bank workers

\begin{tabular}{|lllllll|}
\hline Variables & N & Mean & SD & R & Df & P \\
career commitment of bank workers & 200 & 41.23 & 10.23 & .635 & 198 & Sig \\
achievement motivation & 200 & 52.15 & 16.14 & & & \\
\hline
\end{tabular}

Table 3 shows that achievement motivation significantly correlates with career commitment of bank workers, $r$ $(198)=.635, \mathrm{p}<.05$. The mean and standard deviation for achievement motivation is 52.15 and 16.14 respectively. With this result the Ho: is thus rejected.

\section{Hypothesis Four}

There is no significant relationship between work-value orientations and career commitment of bank workers.

Table 4. PPMC summary showing significant relationship between work-value orientations and career commitment of bank workers

\begin{tabular}{|lllllll|}
\hline Variables & N & Mean & SD & R & Df & P \\
career commitment of bank workers & 200 & 41.23 & 10.23 & .715 & 198 & Sig \\
work-value orientations & 200 & 54.28 & 18.11 & & & \\
\hline
\end{tabular}

Table 4 shows that work-value orientations significantly correlates with career commitment of bank workers, $\mathrm{r}(198)=.715, \mathrm{p}<.05$. The mean and standard deviation for work-value orientation is 54.28 and 18.11 respectively. With this result the Ho: is thus rejected.

\section{Discussion of the Findings}

The study indicates that self-efficacy significantly correlates with career commitment of bank workers $r$ $(198)=.440, p<.05$. This suggests the fact that when bank workers are self-efficacious, they tend to be more productive, result oriented and committed to their career. This is in line with Virginie and Marc (2010) assertion that self-efficacy is highly significant, and is the main predictor of organizational commitment. Perceived efficacy plays a key role in human functioning because it affects behaviour not only directly, but by its impact on other determinants such as goals and aspirations, out come expectations and perception of impediments and opportunities in the social environment (Bandura, 1995, 1997). Self-efficacy also influence the course of action people choose to pursue the challenges and goals they set for themselves and their commitment to them, how much effort they put forth in a given endeavor, the outcomes they expect their efforts to produce and how long they persevere in the face of obstacles. Masood, Rabia and Kashif (2013) found that self-efficacy is fundamental to positive organizational results such as organizational commitment and job satisfaction. Likewise, Dixit and Bhati (2012) believe that employees who are committed to their organization will bring about sustained productivity. Salami (2008) posits that Organizations need committed workers in order to face the worldwide economic competition.

The result of the study shows that emotional intelligence correlates with career commitment of bank workers $\mathrm{r}(198)=.528, \mathrm{p}<.05$. This development indicates that for employees to enjoy their job and be committed to it, they need to develop and express emotional intelligence competence. Working in the bank requires a banker to have the capacity to understand their clients emotions, feelings and be sensitive to their verbal and non verbal attitudinal and behavioural dispositions. If this quality is lacking, bankers could experience frequent frustrating conflict with their customers and this could negatively affect their commitment to their job. Thus, emotional intelligence has been found to be predictive of human behaviour. It is the ability to perceive and express emotion, assimilate emotion in thought, understand and reason with emotion and regulate emotion in the self and others (Mayer et al., 2000). In this regard, Cherniss (2001) reported that emotionally intelligent people display cooperation, commitment and creativity which are important for organizational effectiveness. Emotional intelligence (EI) has been linked to job performance and emotional labour (Prati, 2003; Law et al., 2004). Understanding and regulation of one's emotions as well as understanding other's emotions are factors that affect intrapersonal well-being and interpersonal relations which also affect workers. Some 
researchers found that emotional intelligence was positively correlated with organizational commitment of some workers (Carmeli, 2003; Nikolaou and Tsaousis, 2002; Rozell et al., 2004). Therefore, it is expected that workers having high emotional intelligence will also be highly committed to their organizations.

Also, the result of the study revealed that achievement motivation significantly correlates with career commitment of bank workers, $\mathrm{r}(198)=.635, \mathrm{p}<.05$. This implies that when bank workers achieve their daily target or meet departmental or organisational goal expectations they could feel that sense of fulfilment, accomplishment and satisfaction. In view of these, they would be committed to their career and career advancement. Thus, achievement motivation is the desire to perform in terms of a standard of excellence or to be successful in competitive situations. Persons who have high need for achievement (nAch) assume personal responsibility for the solution of tasks or problems, set moderately difficult goals, take calculated risks, and have strong desire for feedback on their performance as indexed by compensation (Lawson \& Shen, 1998). Researchers found significant relationship between need for achievement and organizational commitment (Dodd-McCue and Wright, 1996; Mannheim et al., 1997).

Furthermore, the findings of the study shows that work-value orientations significantly correlates with career commitment of bank workers, $\mathrm{r}(198)=.715, \mathrm{p}<.05$. This implies that the kind of value experienced and expressed at work environment has positive or negative implication on workers level of commitment to their career. In support of this contention is Sock and Mui (2012) report of the fact that work values explain $17 \%$ of the variance of career commitment. In addition, intrinsic work values are correlated to career commitment at $r=$ .36. Cultural orientation is also found to have significant impact on the work values-career commitment relationship of Generation Y teachers. Also, Shahid, Asif, Mohammad, Muhammad and Ansir (2012) reports that the prominent player in determining the career salience was culture. Culture was a combination of values, beliefs and norms and it is shared among the individuals. Value orientation in any organization mostly focused on internal system of organization and looking for competitive advantage, it encouraged openness to new thoughts and prepared internal capabilities to adopt new ideas, process, or product successfully.

\section{Recommendation}

Based on the findings of this study, the researchers wish to make the following recommendations:

Financial institution(s) should make working in the banks more attractive and rewarding by giving bankers good remuneration, condition of service and appropriate attention to their career needs. If this is done bankers would be motivated to work and be committed to their career.

Bankers should ensure that they develop positive attitude to their career by being ethical, selfless and attentive to the needs of their customers and adhere to the challenging demands of their job by being emotionally literate in their relationship with others.

The bank authorities should ensure that their employees are not unnecessarily stressed with work overload as this could lead to the experience of occupational stress and burnout whose consequence more often than not has negative implication on employees well-being.

\section{Conclusion}

The economy growth of any nation requires the function of an effective financial sector that would help stimulate economic activities. Therefore, it is necessary that the banking industry and their employees are giving the needed support to function efficiently as to enhance societal growth and sustainable development.

\section{References}

[1]. Aborisade, R. \& Obioha, E. E. (2009). "The Role of Motivation in Enhancing Job Commitment in Nigeria Industries: A Case Study of Energy Foods Company Limited, Ibadan,” Journal of Social Sciences, 19/2, 149-154

[2]. Ajiboye, S. O. (2008). Analysis of Causal Factors of Work-Family Role Conflict Among Male and Female Workers. Journal of Sociological Studies, 4 (2), 93 - 104.

[3]. Armstrong M. (2001). Human Resource Management Practice: Handbook, 8th Edition, Kegan Page Ltd., London.

[4]. Bandura, A. (1995). Exercise of personal and collective efficacy in changing societies. In A. Bandura (Ed.), Self-efficacy in changing societies (pp. 1-45). New York, NY: Cambridge University Press.

[5]. Bandura, A. (1997). Self-Efficacy: The Exercise of Control. New York: W. H. Freeman.

[6]. Bandura, A. (1977). Self-efficacy: Toward a unifying theory of behavioral change. Psychological Review, 84, 191-215. http://dx.doi.org/10.1037/0033-295X.84.2.191

[7]. Brockner, J. (1988). The effects of work layoffs on survivors: Research, theory, and practice. In B. M. Staw \& L. L. Cummings (Eds.), Research in organizational behavior: 213-255. Greenwich, CT: JAI.

[8]. Byham, W., \& Moyer, R., (2005). Using Competencies to Build a Successful Organization [Online] Available at: http://www.ddiworld.com/pdf/ddi_usingcompetenciestobuild_mg.pdf [Accessed on 10 December 2010]

[9]. Carmel, A.(2003). The relationship between emotional intelligence and work attitudes, behaviour and outcomes: An examination among senior managers. Journal of Management Psychology, 18(8): 788-813.

[10]. Carson, K. D. \& Bedeian, A. G. (1994). Career Commitment: Construction of a measure and examination of its psychometric properties. Journal of Vocational Behaviour, 44, 237-262.

[11]. Central Bank of Nigeria (2008). Statistical bulletin: Golden jubilee edition - dated 31st December. Abuja: CBN Press 
[12]. Cherniss, C. (2001) Emotional intelligence and organizational effectiveness, (Ch 1), In: C. Cherniss (Ed.): The Emotionally Intelligent Workplace. Retrieved 22nd June 2006 from http://media. wiley. comproduct- data/excerpt/02/07879569/ 0787956902.

[13]. Chughtai, A., (2008). Impact of Job Involvement on In-Role Job Performance and Organizational Citizenship Behavior, Journal of Behavioral and Applied Management, 9(4) [Online] Available at: http://www.jbam.org/pubs/jbam/articles/Vol9/no2/JBAM_9_2_4.pdf [Accessed on 10 December 2010]

[14]. De Witte, H. (2004). Ideological orientation and values. In C. Spielberger (Ed.), Encyclopedia of applied psychology (Vol. 2, pp. 249-258). New york: Elsevier.

[15]. Dixit V. \& Bhati, M. (2012) A study about Employee Commitment and its impact on sustained productivity in Indian Autocomponent Industry. European Journal of Business and Social Sciences volume 1, No.6, pp 34-51

[16]. Dodd-McCue, D. \& Wright, G. B. (1996) Men, women and attitudinal commitment: The effects of workplace experiences and socialization. Human Relations, 49: 1065-1089.

[17]. Dogon-Daji, S. D.H., (2003). Distress in Nigerian banking industry: Causes, effects and remedies. Management Network Journal 2 (4), pp.16-31.

[18]. Dose, J. J. (1997). Work values: An integrative framework and illustrative application to organizational socialization. Journal of Occupational and Organizational Psychology, 70, 219-240.

[19]. Ebiringa, O. T, (2011) Optimal business decision system for multifunctionals: a multifactor analysis of selected manufacturing firms, Serbian Journal of Management, 6 (1) : 17-26.

[20]. Ebong, B. B., (2006). Banking sector reforms: Opportunities and challenges. Union Digest - An Economic and Business Publication of Union Bank of Nigeria Plc 10 (1 \& 2), pp. 1-9.

[21]. Gbadamosi, G. (2003). HRM and the Commitment Rhetoric: Challenges for Africa. Management Decision, vol.41, no.3, pp.274280

[22]. Grouzet, F. M. E., Kasser, T., Ahuvia, A., Dols, J. M., Kim, Y., Lau, S., Ryan, R. M., Saunders, S., Schmuck, P., \& Sheldon, K. (2005). The structure of goals across 15 cultures. Journal of Personality and Social Psychology, 89, 800-816.

[23]. Hartline M. D. \& Ferrell O. C. (1996) 'The Management of Customer Contact Service Employees: An Empirical Investigation', Journal of Marketing, v60, October, pp 52-70

[24]. Ivancevich, J. M., Konopaske, R., \& Matteson, M. T. (2005). Organizational behavior and management (7th ed.). New York, NY: McGraw-Hill/Irwin.

[25]. Knoop, R. (1994). The relationship between importance and achievement of work values and job satisfaction. Perceptual and Motor Skills, 79, 595-605.

[26]. Kreitner, R., \& Kinicki, A. (2004). Organizational behavior (6 $6^{\text {th }}$ ed.). New York, NY: McGraw-Hill.

[27]. Lang, J.W.B., \& Fries, S. (2006). A revised 10-item version of the Achievement Motives Scale. Psychometric properties in German-speaking samples. European Journal of Psychological Assessment, 22, 216-224.

[28]. Law, K.S., Wong, C. \& Song, L. J. (2004) The construct and criterion validity of emotional intelligence and its potential utility for management studies. Journal of Applied Psychology, 89(3): 483-496.

[29]. Lawson, R. B. \& Shen, Z. (1998) Organizational Psychology: Foundation and Applications. Oxford University Press, New York.

[30]. Li, L. (2006) Human motivation in the work organization: Theories and implications. New Asia College Academic Annual, XIX: 253-263. Retrieved 13th July 2006 from http://www.cqmextra.cqm.org/ cqmjournal.nsf/reprints/ rp11300-72k.

[31]. Malka, A., \& Chatman, J. A. (2003). Intrinsic and extrinsic work orientations as moderators of the effect of annual income on subjective well-being: A longitudinal study. Personality and Social Psychology Bulletin, 29, 737-746.

[32]. Mannheim, B., Baruch, Y. \& Tal, J.(1997). Alternative models for antecedents and outcomes of work centrality and job satisfaction of high-tech personnel. Human Relations, 50(2): 1537-1562.

[33]. Masood U. H, Rabia K \& Kashif N (2013) The Effects of Personal Characteristics on Organizational Commitment. Through Job Satisfaction: An Empirical Study of Pakistan's Financial Sector. Middle-East Journal of Scientific Research 16 (7): 942-951, 2013 ISSN $1990-9233$

[34]. Mayer, J. D., Salovey, P. \& Caruso, D. R (2000). "Emotional intelligence as zeitgeist, as personality, and as a mental ability", pp. 92-117. In: The Handbook of Emotional Intelligence: Theory, Development, Assessment and Application at Home, School, and in the Workplace. R. Bar-On and J.D.A. Parker (Eds.). Josey-Bass, San Francisco.

[35]. Meyer, J. P, Allen N. J, Gellatly, I. R, Goffin L, \& Jackson N. A (2000). Affective and continuance commitment to the organization: Evaluations of measures and analyses of concurrent and time-lagged relations. Journal of Applied Psychology 75: 710-720.

[36]. Meyer, J. P., \& Allen, N. J. (1997). Commitment in the Workplace: Theory, Research and Application. London: Sage.

[37]. Meyer, J. P. \& Herscovitch, L. (2001). Commitment in the workplace toward a general model. Human Resource Management Review, 11, 299-326.

[38]. Nikolaou, I. \& Tsaousis, I (2002) Emotional intelligence in the workplace: Exploring its effects on occupational stress and organizational commitment. International Journal of Organizational Analysis, 10(4): 327-342.

[39]. Oishi, S., Schimmack, U., Diener, E., \& Suh, E. M. (1998). The measurement of values and individualism-collectivism. Personality and Social Psychology Bulletin, 11, 1177-1189.

[40]. Prati, L.M.: (2004) Emotional Intelligence as a Facilitator of the Emotional Labor Process. A Dissertation submitted to the Department of the Management in partial fulfillment of the requirement for the Degree of Doctor of Philosophy. The Florida State University, College of Business.

[41]. Ramlall, S. (2002), "a review of employee motivation theories and their implications for employee retention with in organizations", The Journal of American Academy of Business, Cambridge

[42]. Rohan, M. J. (2000). A rose by any name? The values construct. Personality and Social Psychology Review, 4, 255-277.

[43]. Rozell, E.J., Pettijohn, C.E. \& Parker, R.S (2004) Customeroriented selling: Exploring the roles of emotional intelligence and organizational commitment. Psychology and Marketing, 21(6): 405-424.

[44]. Salami, S. O. (2008) Demographic and Psychological Factors Predicting Organizational Commitment among Industrial Workers Anthropologist, vol.10, no.1, pp.31-38

[45]. Schutte, N. S; Malouff, J.M., Hal, L. E. Haggerty, D. J., Cooper, J. T., Golden, C. J. \& Dornheim L. (1998) Development and Validation of a Measure of Emotional Intelligence". Personality and Individual Differences, 25, $167-177$.

[46]. Schwarzer, R., \& Jerusalem, M. (1995). Generalized Self-Efficacy scale. In J. Weinman, S. Wright, \& M. Johnston, Measures in health psychology: A user's portfolio. Causal and control beliefs (pp. 35-37). Windsor, England: NFER-NELSON.

[47]. Shahid, Asif, Mohammad, \& Ansir (2012) Impact of organizational culture on employee's career salience: International Journal of Business and Social Science Vol_3_No_7 
Self-Efficacy, Emotional Intelligence, Achievement Motivation and Work- Value Orientation ....

[48]. Schwartz, S. H. (1994). Are there universal aspects in the structure and contents of human values? Journal of Social Issues, 50, 1945.

[49]. Sock L.C \& Mui H.K, D (2012) Work Values-Career Commitment Relationship of Generation YTeachersinMalaysia. International Proceedings of Economics Development \& Research;2012, Vol. 28, p242

[50]. Solomon, N. (ed.) 2001, Workplace Learning as a Cultural Technology, Jossey-Bass, San Francisco.

[51]. Strain, C., (1995) Need for Autonomy as a Moderating variable in the Model of the Determinants of Salesperson Performance [Online] Available at: http://www.sbaer.uca.edu/research/swma/1995/pdf/08.pdf [Accessed on 9 December 2010]

[52]. Tahir Jamal.et.al (2008), "a Comparison of Intrinsic and Extrinsic Compensation Instruments in the Banking Sector of Pakistan"

[53]. Virginie M (2010) A Study of the effect of national culture value and self-efficacy on organizational commitment in Haiti. Graduate Institute Human Resource Development 